\title{
Characterization of iron oxide waste scales obtained by rolling mill steel industry
}

\author{
J. Kargin ${ }^{1} \cdot$ L. De Los Santos Valladares ${ }^{1,2,3,4}$. L. E. Borja-Castro ${ }^{4}$ Jiang Xize ${ }^{3}$. \\ D. G. Mukhambetov ${ }^{5}$. Y. V. Konyukhov ${ }^{6} \cdot$ N. O. Moreno ${ }^{7}$.
}

A. G. Bustamante Dominguez ${ }^{4}$. C. H.W. Barnes ${ }^{2}$

Accepted: 15 February 2022 / Published online: 1 March 2022

(c) The Author(s) 2022

\begin{abstract}
Every year, the steelmaking industry produces millions of tons of slags resulting in pollution to the environment. Among the waste, secondary metals and scales rich in iron oxides are also thrown away. There is a need to treat the steel waste in a reasonably way to protect the environment and proposing new cheap technologies for producing advanced materials. In this study we report the morphological and structural characterization of waste scales generated during roll milling steel process at JSC "Arcelor Mittal Temirtau". The raw slag and annealed at $1000{ }^{\circ} \mathrm{C}$ were measured by X-ray diffraction (XRD), scanning electron microscopy adapted with energy dispersive X-ray (SEM- EDX), magnetometry and Mössbauer Spectroscopy (MS). Fe and $\mathrm{O}$ were detected by EDX as main chemical elements and $\mathrm{Si}, \mathrm{S}, \mathrm{Ca}, \mathrm{Mg}, \mathrm{C}$ and $\mathrm{Al}$ as minimal elemental composition. XDR for the raw sample revealed $\alpha-\mathrm{Fe}_{2} \mathrm{O}_{3}$ (hematite) and $\mathrm{Fe}_{3} \mathrm{O}_{4}$ (magnetite) as principal and secondary phase, respectively; whereas monophasic $\alpha-\mathrm{Fe}_{2} \mathrm{O}_{3}$ is detected for the scales annealed at $1000{ }^{\circ} \mathrm{C}$. Magnetometry measurements show the Verwey transition for the raw sample and the Morin transition for the annealed at $1000{ }^{\circ} \mathrm{C}$; those are fingerprints for the presence of magnetite and hematite, respectively. MS measurements for the raw sample consist of 6 small peaks of absorption and a broad two-lines absorption peak in the central part. The doublets are associated to the hyperfine parameters belonging to wustite. Magnetite is related to the hyperfine parameters for two sextets in octahedral $\mathrm{Fe}^{2.5+}$ and tetrahedral $\mathrm{Fe}^{3+}$ sites and a small sextet that resembles the Mössbauer parameters of $\alpha-\mathrm{Fe}_{2} \mathrm{O}_{3}$. Only a well crystallized and weakly ferromagnetic sextet confirm the presence of $\alpha-\mathrm{Fe}_{2} \mathrm{O}_{3}$ phase for the sample annealed at $1000{ }^{\circ} \mathrm{C}$ due to thermal oxidation.
\end{abstract}

Keywords Iron oxide $\cdot$ Steel slag $\cdot$ Steel scales $\cdot$ Rolling mill steel $\cdot$ Mössbauer spectroscopy

This article is part of the Topical Collection on Proceedings of the International Conference on the Applications of the Mössbauer Effect (ICAME 2021), 5-10 September 2021, Brasov, Romania Edited by Victor Kuncser

L. De Los Santos Valladares

1d301@cam.ac.uk; luis_d_v@hotmail.com

Extended author information available on the last page of the article 


\section{Introduction}

During the industrial production of iron steel, tons of iron-rich scales are produced as waste materials [1]. Since the waste contains large amounts of iron oxides, heavy metals and other different contaminants, it affects the environment when disposed in landfills because it releases toxic substances in soil and groundwater [2]. Thus, steel wastes create pollution to the environment. If these resources are reasonably treated, then not only the environment would be protected and disposal costs reduced, but also proposing new cheap technology for producing advanced materials [3]. Some attempts in re-using waste materials from steel industry includes iron oxide pigments, new metal pieces, manufacturing equipment, chemical tankers, automotive and airplane components [4, 5].

For the recycling, the steel waste should be previously treated in different ways, such as grinding, pressing, bathing, vitrifying, annealing, and other related procedures under various conditions of pressure, atmosphere and temperature [1, 6, 7]. For example, annealing promotes the oxidation of iron such as hematite $\left(\alpha-\mathrm{Fe}_{2} \mathrm{O}_{3}\right)$ and magnetite $\left(\mathrm{Fe}_{3} \mathrm{O}_{4}\right)$ and then the iron components can be separated magnetically. In this way, it is very important to know the composition and characteristics of the waste materials before attempting to recycle them [1] [8-11]. Carlini et al. have observed that by regulating the number of iron ions in the body and limiting the crystallization process, it is possible to obtain materials with conductivity less than $1000 \Omega$ [3]. Also, it has been reported that the formation of nanoor micro-scale crystals gives iron oxide certain outstanding properties, such as electrical conductivity and ferromagnetism [6]. Moreover, the characteristics of pigments obtained from recycled iron oxides are greatly affected by the grinding, milling and heat treatment processes and also by hematite content [2]. In addition, oxide scales obtained during rolling have different magnetic properties after magnetic separation [6].

Therefore, for a correct recycling and application of industrial steel waste, it is necessary to have good information on its composition, characteristics and properties. In this work, we report the characterization of iron oxide waste scales obtained by rolling mill steel industry. The sample was obtained during the mechanical cleaning of the surface of hot-rolled steel strip in the production process. This is a promising prime material since its price is much cheaper than hematite powder obtained during the pyrolysis of spent pickling solutions.

\section{Experimental}

The scales formed on the surface of steel sheets during the hot rolling process $(\mathrm{T} \sim 700$ $1200{ }^{\circ} \mathrm{C}$ ) of steelmaking were collected [12]. It consists of mill scales of wustite $(\mathrm{FeO})$, magnetite $\left(\mathrm{Fe}_{3} \mathrm{O}_{4}\right)$ and hematite $\left(\alpha-\mathrm{Fe}_{2} \mathrm{O}_{3}\right)$. The collected sample was also annealed at $1000{ }^{\circ} \mathrm{C}$ in air. The morphology of the samples was inspected through a scanning electron microscope (SEM) Philips XL-30 equipped with an EDX X-MAX $\left(80 \mathrm{~mm}^{2}\right)$ Oxford Instruments Inc. and acceleration voltages of $20-30 \mathrm{kV}$. The X-ray diffraction (XRD) were taken in a Rigaku diffractometer with $\mathrm{Cu}-\mathrm{K} \alpha$ radiation $\lambda=1.5409 \AA$ with $20^{\circ}<2 \theta<90^{\circ}$, 0.01 step and scanning speed of $0.01 \%$ s. The current was $200 \mathrm{~mA}$. Mössbauer spectroscopy (MS) measurements at room temperature were carried out using a Mössbauer spectrometer in transmission geometry. A ${ }^{57} \mathrm{Co}$ source in $\mathrm{Rh}$ matrix with $50 \mathrm{mCi}$ of nominal activity moving at constant acceleration. For the calibration measurement, a thin foil $\alpha$-Fe standard 
sample was used. The fitting process was achieved applying least square theory with Lorentzian profiles in the WinNormos software. The magnetic measurements were performed using a DC-MPMS-SQUID magnetometer (Quantum Design Inc.) in zero-field cooling (ZFC) and field cooling (FC) modes. The magnetization response as a function of the temperature was collected from 5 to $400 \mathrm{~K}$ and applying external magnetic fields between 100 Oe to $10 \mathrm{kOe}$. The magnetization responses as a function of an external applied magnetic field were also measured in the range $\pm 10 \mathrm{kOe}$ and at different temperatures between 5 to $400 \mathrm{~K}$.

\section{Results and discussion}

Figure 1 displays the SEM micrographs and the EDX spectra of the raw scales and after annealing at $1000{ }^{\circ} \mathrm{C}$. The SEM micrographs of the raw sample (see Fig. 1(a)) reveal that the morphology of the scales has lamellar shapes of different sizes, ranging from millimeters to several centimeters. They are flat and spread without sticking together. Figure 1b) is a zoomed view which reveals that the scales are composed of grains with planar fractured faces and stuck together. The faces of the grains are smooth suggesting good crystallinity although the grain boundary is not appreciable. Figures 1 ( $c$ and d) show the micrograph of the samples after annealing at $1000{ }^{\circ} \mathrm{C}$. The high temperature provokes that the sample becomes a lump. The scale morphology is lost and the grains tend to stick together; the faceted grains decrease their size suggesting melting in the grain interfaces. In Fig. 1e) the EDX mapping spectra for the raw sample shows that the main elemental components are $\mathrm{Fe}$ and $\mathrm{O}$, suggesting the presence of iron oxides as main mineralogical phases. Note that some spots of $\mathrm{Ca}$ are spread over the samples. Table 1 lists the quantification of the main elements obtained by EDX. Ca may proceed for the non-reacted calcium carbonate added during the steelmaking process [13]. In addition, other minor elements, such as $\mathrm{Si}$ and $\mathrm{Al}$ are found and might belong to silicates and aluminosilicates coming from soil dust present in the collection zone. Figure 1f) shows the EDX mapping of the scales after annealing at $1000{ }^{\circ} \mathrm{C}$. Similarly, to the previous case, $\mathrm{Fe}$ and $\mathrm{O}$ are the main compositional elements. Note that in addition to the $\mathrm{Si}, \mathrm{Al}$ and $\mathrm{Ca}$ assumed from silicates from soil dust, other minor components, such as $\mathrm{Mg}, \mathrm{Cr}$ and $\mathrm{C}$ appear. Carbon could come from contaminants from the furnace processing, $\mathrm{Mg}$ might come from remaining unreacted compounds during processing the iron steel, while $\mathrm{S}$ was added during steelmaking to improve machinability [14].

Figure 2 shows the X-ray diffraction for the collected scales and for the samples annealed at $1000{ }^{\circ} \mathrm{C}$. The main phase for the raw sample is $\alpha-\mathrm{Fe}_{2} \mathrm{O}_{3}$ (hematite). Some tiny peaks reflections are also found between $25^{\circ}$ and $33^{\circ}$, indicated in bold filled squares, which could be related to some silicates compounds according to the EDX results above. The diffraction pattern of the sample obtained after annealing at $1000{ }^{\circ} \mathrm{C}$ shows only hematite phase. Note that some peaks become sharper, indicating that the crystallization of the hematite has improved. Miller indexes, angles, full width at the half maximum (FWHM), and crystallite sizes obtained from the XRD are listed in Table 2. FWHM tends to decrease its values meanwhile the grain size increases due to thermal heating. This indicates that hematite crystals grow by thermal induction.

Note that at higher angles than $75^{\circ}$, the peaks belonging to the (220), (036), (128), (0 0 12), and (226) reflections appear (enclosed by the dash squares). This also confirms the improvement in crystallization of the hematite phase due to the oxidation of other possible 

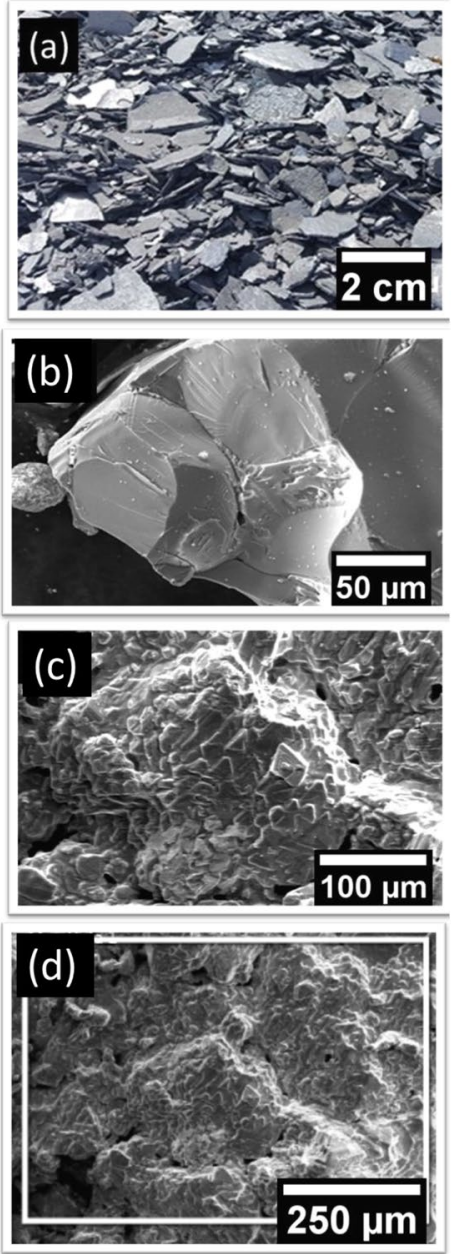
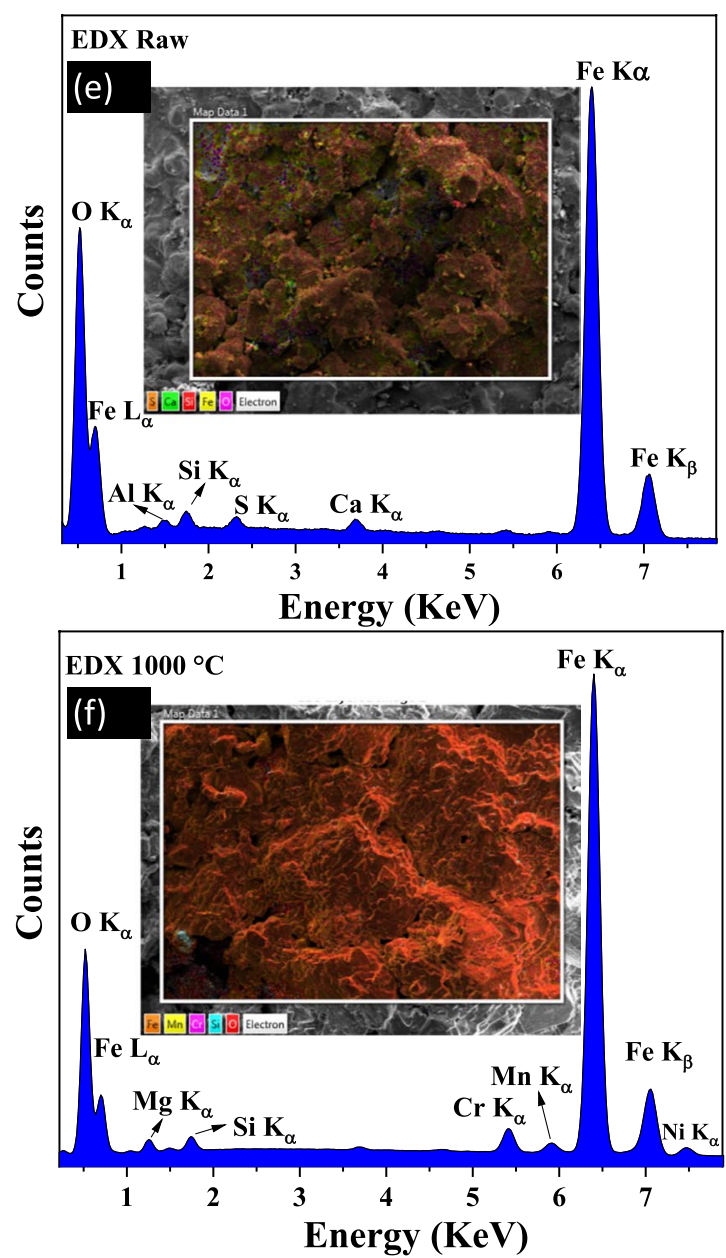

Fig. 1 SEM micrographs and EDX analysis of iron oxide waste scale obtained by rolling mill steel industry and after annealed at $1000{ }^{\circ} \mathrm{C}$. a) and (b) micrographs of the collected scale samples and (c), (d) micrographs for the annealed sample at $1000{ }^{\circ} \mathrm{C}$. (e) and (f) EDX for raw sample and after annealing at $1000{ }^{\circ} \mathrm{C}$

Table 1 Elemental quantification in percentage weight (wt\%) obtained by EDX analysis for iron oxide waste scales obtained by rolling mill steel industry and after annealing at $1000{ }^{\circ} \mathrm{C}$

\begin{tabular}{llllllllll}
\hline Sample & $\mathrm{O}$ & $\mathrm{Fe}$ & $\mathrm{Si}$ & $\mathrm{C}$ & $\mathrm{S}$ & $\mathrm{Ca}$ & $\mathrm{Al}$ & $\mathrm{Cr}$ & $\mathrm{Mg}$ \\
\hline Raw & 24.26 & 72.9 & 0.91 & & 0.59 & 0.71 & 0.62 & & \\
& \pm & \pm 0.13 & \pm 0.03 & & \pm & \pm & \pm & & \\
& 0.12 & & & & 0.03 & 0.03 & 0.04 & & \\
$1000^{\circ} \mathrm{C}$ & 22.83 & 65.89 & 1.01 & 3.39 & & 0.17 & 0.3 & $1.99 \pm$ & 1.83 \\
& \pm 0.10 & \pm 0.13 & \pm 0.01 & \pm & & \pm & \pm & 0.01 & \pm \\
& & & & 0.13 & & 0.01 & 0.01 & & 0.02 \\
\hline
\end{tabular}


Fig. 2 Xray Diffractogram of iron oxide waste scales obtained by rolling mill steel industry and after annealing at $1000{ }^{\circ} \mathrm{C}$

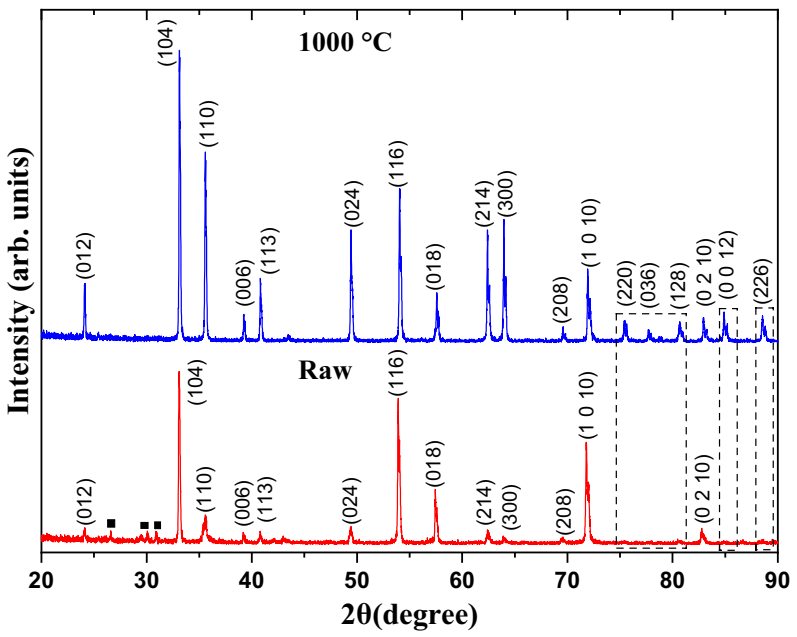

minor iron oxides components. In this case, the presence of those peaks indicate the complete oxidation of magnetite [15], as detected by the other techniques below.

The temperature dependence of the magnetization $(\mathrm{M}(\mathrm{T}))$ curves for the raw scales obtained during rolling mill process of steel industry is given in Fig.3 (a). The M(T) curves show decrease of irreversibility in ZFC and FC as the applied external field is increased between $100 \mathrm{Oe}$ to $5 \mathrm{kOe}$. Increasing the applied external field provokes the alignment of more magnetic domains and resulting in the gaining of magnetization. Moreover, at each external applied magnetic field, the $\mathrm{M}(\mathrm{T})$ responses show the Verwey transition at $\mathrm{T} \sim 124 \mathrm{~K}$ which is the usual fingerprint to identify magnetite [16]. Note that the XRD analysis above detects also hematite for this sample. However, since the magnetization values for hematite are very low, it could be screened by that for magnetite and others magnetic phases.

The $\mathrm{M}(\mathrm{T})$ responses for the scales annealed at $1000{ }^{\circ} \mathrm{C}$ are given in Fig. 3 (b). They show low magnetization values compared to the raw sample (see Fig. 3 (a)). The Verwey transition is not detected anymore and instead, the Morin transition remarkably appears. The Morin transition is the fingerprint signal for presence of hematite [17]. It is not screened at higher external fields meaning that any other ferromagnetic or anti-ferromagnetic domains are not present. Nevertheless, there is a paramagnetic signal, which becomes noticeable when increasing the external magnetic field. These results confirm that magnetite oxidizes by thermal induction after annealing at $1000{ }^{\circ} \mathrm{C}$ into hematite [15].

Figure 3 (c) shows the applied magnetic field dependence of the magnetization $\mathrm{M}(\mathrm{H})$ for the raw sample. It reveals hysteresis, typical of soft ferromagnetic material. The inset in Fig. 3 (c) displays the remanence magnetization values that decays with increasing temperature. However, the variation of remanence values does not show a clear tendency between 150 and 275 K. Similar behaviour is observed in coercivity values (see inset in Fig. 3 (c) for raw samples). The decreases in remanence and coercivity values is due to the competition between thermal and magnetic energy in magnetic domains. That is, at low temperatures, thermal energy decreases, making spins stand fixed (high coercivity) resulting in more difficulty to reorient them. However, the variation in both remanence and coercivity in the temperature range between 150 and $175 \mathrm{~K}$ does not follow a defined trend. This indicates an incoherent spin rotation mode which must be caused by competition between 
Table 2 Miller indexes, angles, FWHM, and crystallite sizes obtained from the XRD for the iron scales produced during the industrial production of steels

\begin{tabular}{|c|c|c|c|c|}
\hline Sample & (hkl) & $2 \Theta\left({ }^{\circ}\right)$ & FWHM $\left(^{\circ}\right)$ & Size $(\mathrm{nm})$ \\
\hline \multirow[t]{12}{*}{ Raw } & (012) & 24.11 & 0.28 & 29 \\
\hline & (104) & 33.11 & 0.18 & 46 \\
\hline & (110) & 35.55 & 0.47 & 18 \\
\hline & (006) & 39.24 & 0.21 & 40 \\
\hline & (113) & 40.8 & 0.17 & 49 \\
\hline & (024) & 49.42 & 0.27 & 32 \\
\hline & (116) & 53.97 & 0.26 & 40 \\
\hline & (018) & 57.51 & 0.27 & 33 \\
\hline & (214) & 62.45 & 0.34 & 27 \\
\hline & (300) & 64 & 0.36 & 26 \\
\hline & $\left(\begin{array}{lll}1 & 0 & 10\end{array}\right)$ & 71.87 & 0.4 & 24 \\
\hline & $\left(\begin{array}{lll}0 & 2 & 10\end{array}\right)$ & 82.83 & 0.39 & 27 \\
\hline \multirow[t]{18}{*}{$1000{ }^{\circ} \mathrm{C}$} & (012) & 24.12 & 0.15 & 54 \\
\hline & (104) & 33.14 & 0.15 & 55 \\
\hline & (110) & 35.59 & 0.14 & 59 \\
\hline & (006) & 39.27 & 0.17 & 49 \\
\hline & (113) & 40.85 & 0.19 & 44 \\
\hline & (024) & 49.46 & 0.22 & 39 \\
\hline & (116) & 54.11 & 0.22 & 40 \\
\hline & (018) & 57.62 & 0.27 & 33 \\
\hline & (214) & 62.44 & 0.26 & 34 \\
\hline & (300) & 64.01 & 0.28 & 33 \\
\hline & (208) & 69.59 & 0.12 & 80 \\
\hline & $\left(\begin{array}{lll}1 & 0 & 10\end{array}\right)$ & 72.01 & 0.33 & 29 \\
\hline & (220) & 75.43 & 0.16 & 62 \\
\hline & (036) & 77.81 & 0.29 & 35 \\
\hline & (128) & 80.72 & 0.38 & 27 \\
\hline & $\left(\begin{array}{lll}0 & 2 & 10\end{array}\right)$ & 82.96 & 0.2 & 52 \\
\hline & $\left(\begin{array}{lll}0 & 0 & 12\end{array}\right)$ & 84.91 & 0.21 & 51 \\
\hline & (226) & 88.71 & 0.43 & 26 \\
\hline
\end{tabular}

the magnetic moments of the different components of the sample [18]. This effect does not happen in scales obtained by rolling mill annealed at $1000{ }^{\circ} \mathrm{C}$ because the major component is hematite, as it is discussed next.

Figure $3(\mathrm{~d})$ shows the applied field dependence of the magnetization $(\mathrm{M}(\mathrm{H}))$ loops for the annealed sample. They reveal hysteresis due to the presence of hematite coexisting with paramagnetic domains. Note that the hysteresis loops near the Morin temperature at $\mathrm{T} \sim 275 \mathrm{~K}$ show deformed hysteresis. That is, near zero applied field, the hysteresis curves are less wide than with increasing external magnetic field (see bottom inset plots). This is due to the presence of weak antiferromagnetic and ferromagnetic domains at this temperature [18]. Note also that, according to the top inset plots, the remanence and coercivity values increase slightly above $250 \mathrm{~K}$, this is due to the transition of hematite from antiferromagnetic to weak ferromagnetic.

The RT Mössbauer spectra of the raw scales obtained by rolling mill steel industry and the annealed sample at $1000{ }^{\circ} \mathrm{C}$ are shown in Fig. 4. The spectra were fitted using 
a

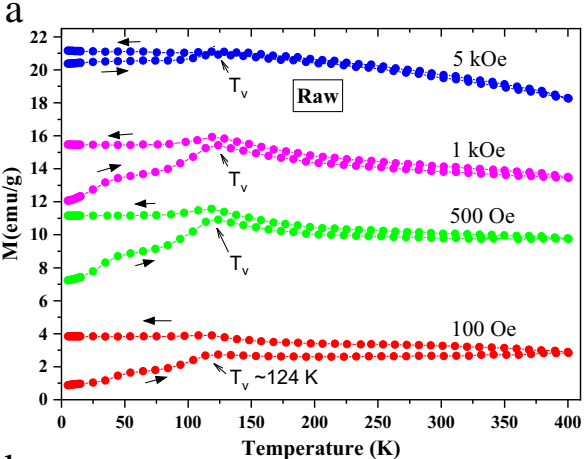

b

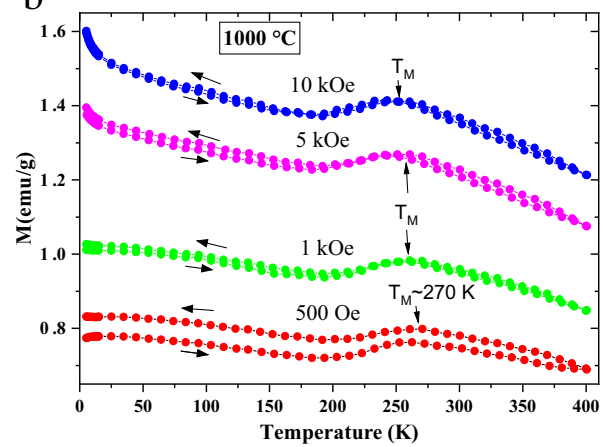

c

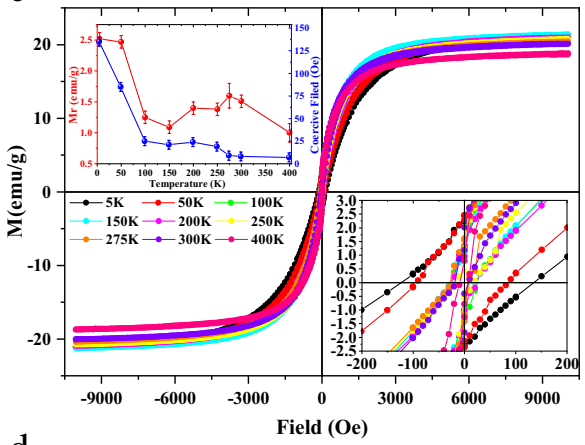

d

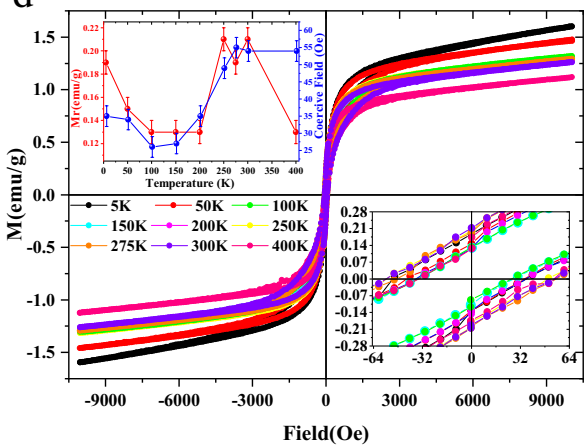

Fig. 3 Magnetic responses of iron oxide waste scales obtained by rolling mill steel industry (a) $\mathrm{M}(\mathrm{T})$, (c) $\mathrm{M}(\mathrm{H})$ for the raw sample, (c) $\mathrm{M}(\mathrm{T})$ and $(\mathbf{d}) \mathrm{M}(\mathrm{H})$ for the sample annealed at $1000{ }^{\circ} \mathrm{C}$

Lorentzian profiles and the resulting hyperfine parameters are listed in Table 3. The Mössbauer spectrum for the raw milled scales, given in the top figure, presents six small absorption peaks and a broad one in the central part, these spectra were adjusted using three sextets and two doublets sites. The two doublets correspond to one paramagnetic dominant fraction with $\mathrm{Fe}^{3+}$ site and relative absorption area (RAA) of $45.9 \%$, and another paramagnetic fraction with $\mathrm{Fe}^{2+}$ site and relative absorption $18.4 \%$. The MS suggest that these two doublets correspond to the presence of wustite with hyperfine parameters $\delta_{\mathrm{Fe}}=0.86 \mathrm{~mm} / \mathrm{s}, \Delta \mathrm{E}_{\mathrm{Q}}=0.71 \mathrm{~mm} / \mathrm{s}$ and $\delta_{\mathrm{Fe}}=1.13 \mathrm{~mm} / \mathrm{s}, \Delta \mathrm{E}_{\mathrm{Q}}=0.63 \mathrm{~mm} / \mathrm{s}$ [19] which cannot be detected by XRD probably by its low quantity. Note that the quantity of $\mathrm{Si}$ is about $1 \%$ so it is no possible to associate it to any iron-silicate minerals. The particles sizes in Fig. 1(a) and (b) are not in the nanometer order and the $M(H)$ curves show hysteresis loops in Fig. 3 meaning that the doublets do not correspond to superparamagnetic domains [20]. The two sextets are related to the octahedral $\mathrm{Fe}^{2.5+}$ and tetrahedral $\mathrm{Fe}^{3+}$ sites with hyperfine parameters $\delta_{\mathrm{Fe}}=0.86 \mathrm{~mm} / \mathrm{s}, 2 \varepsilon=-0.04, \mathrm{~B}_{\mathrm{hf}}=45.9 \mathrm{~T}$ and $21.6 \%$ RAA, and $\delta_{\mathrm{Fe}}=0.27 \mathrm{~mm} / \mathrm{s}, \mathrm{B}_{\mathrm{hf}}=45.9 \mathrm{~T}$ and (RAA) of $12.6 \%$, respectively. Since the magnetic measurements above detected the Verwey transition (see Fig.3 (a)), these hyperfine parameters correspond to magnetite [16, 21], which is in a medium absorption fraction content. Note also that the rate RAA $\left(\mathrm{Fe}^{2.5+}\right) / \mathrm{RAA}\left(\mathrm{Fe}^{3+}\right)$ results in 1.7 , indicating that magnetite is not in a stoichiometric ratio that means that it is partially substituted or oxidized, probably due to environmental interaction. The tiny sextet 


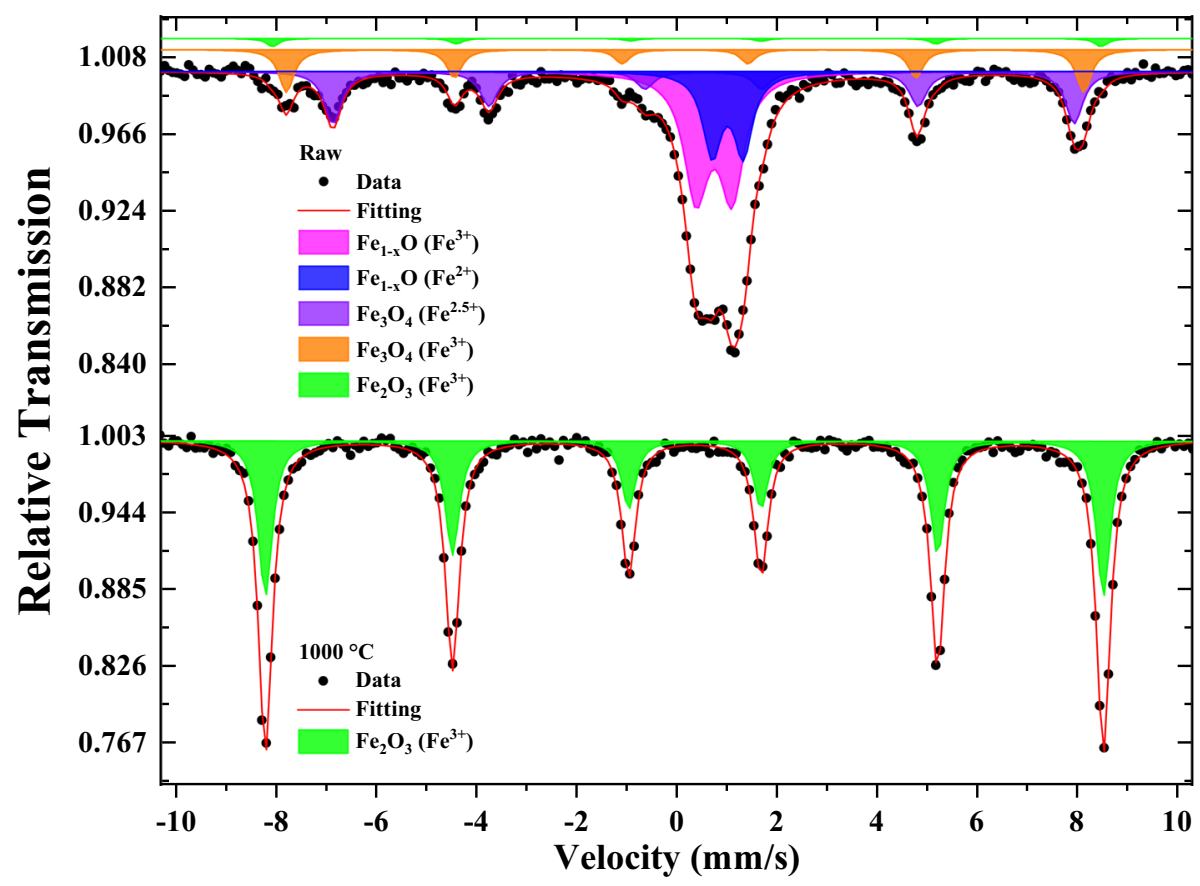

Fig. 4 Room Temperature Mössbauer of iron oxide waste scales obtained by rolling mill steel industry (top) and after annealed at $1000{ }^{\circ} \mathrm{C}$ (bottom)

Table 3 Mössbauer hyperfine parameters of raw iron oxide waste scales obtained by rolling mill steel industry and annealed at $1000{ }^{\circ} \mathrm{C}$

\begin{tabular}{llllllll}
\hline Sample & Subspectra & $\mathrm{Fe}^{+3} / \mathrm{Fe}^{+2}$ & $\delta(\mathrm{mm} / \mathrm{s})$ & $\Delta \mathrm{E}_{\mathrm{Q}} / 2 \varepsilon(\mathrm{mm} / \mathrm{s})$ & $\mathrm{B}_{\mathrm{hf}}(\mathrm{T})$ & $\Gamma(\mathrm{mm} / \mathrm{s})$ & Area (\%) \\
\hline Raw & Wustite & $\mathrm{Fe}^{2+}$ & 0.86 & 0.71 & - & 0.6 & 45.9 \\
& & $\mathrm{Fe}^{2+}$ & 1.13 & 0.63 & - & 0.46 & 18.4 \\
& Magnetite & $\mathrm{Fe}^{2.5+}$ & 0.65 & -0.04 & 45.9 & 0.44 & 21.6 \\
& & $\mathrm{Fe}^{3+}$ & 0.27 & - & 49.2 & 0.36 & 12.6 \\
& Hematite & $\mathrm{Fe}$ & 0.32 & -0.23 & 51.7 & 0.3 & 1.5 \\
$1000{ }^{\circ} \mathrm{C}$ & Hematite & $\mathrm{Fe}^{3+}$ & 0.37 & -0.21 & 51.8 & 0.34 & 100 \\
\hline
\end{tabular}

with hyperfine parameters of $\delta_{\mathrm{Fe}}=0.32 \mathrm{~mm} / \mathrm{s}, 2 \varepsilon=-0.23, \mathrm{~B}_{\mathrm{hf}}=51.7 \mathrm{~T}$ and (RAA) of $1.5 \%$ is related to hematite [22] as detected by the XRD above. However, in contrast to the XRD analysis above which detects hematite as major mineral component and similarly to the magnetometry analysis above, the tiny sextet in the MS corresponding to hematite must be screened by the magnetite sub-spectra.

Regarding the scales annealed at $1000{ }^{\circ} \mathrm{C}$, in agreement to the analysis by the other techniques above, which reveal the presence of monophasic hematite; the resultant MS spectrum consists of one sextet with hyperfine parameters $\delta_{\mathrm{Fe}}=0.37 \mathrm{~mm} / \mathrm{s}, 2 \varepsilon=-0.21$, $\mathrm{B}_{\mathrm{hf}}=51.8 \mathrm{~T}$ and (RAA) of $100 \%$ which correspond to hematite. This confirms the thermal oxidation from wustite to magnetite and to hematite improving crystallization [15]. 


\section{Conclusions}

Iron oxide waste scales obtained by rolling mill steel industry was annealed at $1000{ }^{\circ} \mathrm{C}$ and characterized by different techniques. Fe and $\mathrm{O}$ are the major elemental composition and $\mathrm{Si}, \mathrm{S}, \mathrm{Mg}, \mathrm{Cr}$ and $\mathrm{Ca}$ are the minimal components for the raw and annealed at $1000{ }^{\circ} \mathrm{C}$ samples indicating they consist mainly in iron oxides. $\alpha-\mathrm{Fe}_{2} \mathrm{O}_{3}$ and $\mathrm{Fe}_{3} \mathrm{O}_{4}$ were the iron oxides detected for the raw sample scales, whereas $\alpha-\mathrm{Fe}_{2} \mathrm{O}_{3}$ was the only iron oxide identified for the annealed sample at $1000{ }^{\circ} \mathrm{C}$. Verwey transition, associated to magnetite content in the raw sample was registered in the $\mathrm{M}(\mathrm{T})$ curves under $100 \mathrm{Oe}, 500 \mathrm{Oe}, 1 \mathrm{kOe}$ and $5 \mathrm{kOe}$ external fields with high values of magnetization that screen the magnetic signal from hematite. The $\mathrm{M}(\mathrm{H})$ loops present hysteresis due to ferromagnetic domains. For the sample annealed at $1000{ }^{\circ} \mathrm{C}$ only hematite was registered by its Morin transition in the magnetic analysis. However, the hyperfine parameters confirm the presence of wustite and magnetite in non-stequeometric state, and also hematite. Additionally, the MS reveals the formation of hematite for the annealed sample at $1000{ }^{\circ} \mathrm{C}$ due to oxidation of magnetite.

Acknowledgements This work was supported by the CONCYTEC - World Bank - FONDECYT program "Incorporación de Investigadores", Contract No. 12 -2019 - FONDECYT - BM - INC. INV.

Open Access This article is licensed under a Creative Commons Attribution 4.0 International License, which permits use, sharing, adaptation, distribution and reproduction in any medium or format, as long as you give appropriate credit to the original author(s) and the source, provide a link to the Creative Commons licence, and indicate if changes were made. The images or other third party material in this article are included in the article's Creative Commons licence, unless indicated otherwise in a credit line to the material. If material is not included in the article's Creative Commons licence and your intended use is not permitted by statutory regulation or exceeds the permitted use, you will need to obtain permission directly from the copyright holder. To view a copy of this licence, visit http://creativecommons.org/licenses/by/4.0/.

\section{References}

1. Ruhiyuddin, M.Z., Murizam, D., Ahmad, K.R.: Synthesis and characterization of iron produced from iron mill scale. Key Eng. Mater. 594-595, 118-122 (2014). https://doi.org/10.4028/www.scientific.net/ KEM.594-595.118

2. Prim, S.R., Folgueras, M.V., de Lima, M.A., Hotza, D.: Synthesis and characterization of hematite pigment obtained from a steel waste industry. J. Hazard. Mater. 192, 1307-1313 (2011). https://doi.org/ 10.1016/j.jhazmat.2011.06.034

3. Carlini, R., Alfieri, I., Zanicchi, G., Soggia, F., Gombia, E., Lorenzi, A.: Synthesis and characterization of Iron-rich glass ceramic materials: A model for steel industry waste reuse. J. Mater. Sci. Technol. 32, 1105-1110 (2016). https://doi.org/10.1016/j.jmst.2016.09.008

4. Legodi, M.A., de Waal, D.: The preparation of magnetite, goethite, hematite and maghemite of pigment quality from mill scale iron waste. Dyes Pigments. 74, 161-168 (2007). https://doi.org/10.1016/j. dyepig.2006.01.038

5. Villasante Miranda, A.G., Borja Castro, L.E., Valencia-Bedregal, R.A., Espinoza Suarez, S.M., Valerio-Cuadros, M.I., Bustamante Domínguez, A., Zhao, X., Zhang, Y., Zheng, C., Barnes, C.H.W., Zhang, D., De Los Santos Valladares, L.: Characterization of recycled Q235 steel chips from rolling billet scales. Hyperfine Interactions. 7 (2021). https://doi.org/10.1007/s10751-021-01764-0

6. Lorenzi, A., Rastelli, D., Biavati, A., Poncini, M., Alfieri, I., Albertini, F., Gombia, E., Romaniello, L., Montenero, A.: Immobilization of iron rich steel industry waste and products characterization. J Environ Chem Eng. 3, 196-201 (2015). https://doi.org/10.1016/j.jece.2014.11.024

7. Espinoza Suarez, S.M., Borja-Castro, L.E., Valerio-Cuadros, M.I., Bustamane Domínguez, A., Cabrera-Tinoco, H.A., Huaman, E., Valencia-Bedregal, R.A., Zhao, X., Zhang, Y., Zhang, D., Barnes, C.H.W., Valladares, D.L.S., L.: Carbothermal reduction of mill scales formed on steel billets during continuos casting. Hyperfine Interactions. 12, (2021). https://doi.org/10.1007/s10751-021-01769-9 
8. Bustamante Dominguez, A.G., Valerio-Cuadros, M I, Borja-Castro, L E, Valencia-Bedregal, R A, Flores Santibañez, J, Espinoza Suarez, S M, Cabrera-Tinoco, H, Moreno, N O, Barnes, C H W, De Los Santos Valladares, L.: Characterization and Mössbauer spectroscopy of steel slag generated in the ladle furnace in SIDERPERU steel plant. Hyperfine Interactions 2022 243:1. 243, 1-11 (2022). https://doi. org/10.1007/S10751-022-01799-X

9. Valerio-Cuadros, M.I., Dominguez, A.G.B., Valencia-Bedregal, R.A., Borja-Castro, L.E., Suarez, S.M.E., Cabrera-Tinoco, H.A., Barnes, C.H.W., Valladares, L.D.L.S.: Structural and hyperfine magnetic properties of primary steelmaking slag. Hyperfine Interactions 2022 243:1. 243, 1-7 (2022). https://doi.org/10.1007/S10751-022-01797-Z

10. Cabrera-Tinoco, H.A., Valencia-Bedregal, R.A., Borja-Castro, L.E., Valerio-Cuadros, M.I., Dominguez, A.G.B., Zhao, X., Zhang, Y., Zheng, C., Moreno, N.O., Zhang, D., Barnes, C.H.W., Valladares, L.D.L.S.: Characterization of black slags obtained during smelting in the electric arc furnace from SIDERPERU following reduction. Hyperfine Interactions 2022 243:1. 243, 1-12 (2022). https:// doi.org/10.1007/S10751-022-01791-5

11. Borja-Castro, L.E., Bustamante Dominguez, A., Valerio-Cuadros, M.I., Valencia-Bedregal, R.A., Cabrera-Tinoco, H.A., Espinoza Suarez, S.M., Kargin, J., Moreno, N.O., Barnes, C.H.W., Valladares, L.D.L.S.: Characterization of steel billet scales generated during the continuous casting process in SIDERPERU steel plant. Hyperfine Interactions 2021 242:1. 242, 1-9 (2021). https://doi.org/10.1007/ S10751-021-01778-8

12. Kargin, D.B., Konyukhov, Y.V., Biseken, A.B., Lileev, A.S., Karpenkov, D.Y.: Structure, morphology and magnetic properties of hematite and Maghemite Nanopowders produced from rolling mill scale. Steel in Translation. 50, 151-158 (2020). https://doi.org/10.3103/S0967091220030055

13. Hechavarría, R., López, G.: Fundamentals of steelmaking by E. T. Turkdogan. J. Chem. Inf. Model. 53, 1689-1699 (2013). https://doi.org/10.1017/CBO9781107415324.004

14. Pereira, A.A., Boehs, L., Guesser, W.L.: The influence of sulfur on the machinability of gray cast iron FC25. J. Mater. Process. Technol. 179, 165-171 (2006). https://doi.org/10.1016/j.jmatprotec.2006.03. 100

15. Barrero, C.A., Jerez, A., Restrepo, J., Morales, A.L.: Revista colombiana de fisica, vol. 33, no. 2. 2001 transformación magnetita-hematita inducida térmicamente. 33, 230-233 (2001)

16. Walz, F.: The Verwey transition - A topical review. J Phys Condensed Matter. 14, (2002). https://doi. org/10.1088/0953-8984/14/12/203

17. Nininger Jr., R.C., Schroeer, D.: Mossauer studies of the Morin transition in bulk and microcrystalline alpha-Fe2O3. J Phys Chem Solids. 39, 137-144 (1978)

18. De Los Santos Valladares, L., Bustamante Domínguez, A., León Félix, L., Kargin, J.B., Mukhambetov, D.G., Kozlovskiy, A.L., Moreno, N.O., Flores Santibañez, J., Castellanos Cabrera, R., Barnes, C.H.W.: Characterization and magnetic properties of hollow $\alpha-\mathrm{Fe}_{2} \mathrm{O}_{3}$ microspheres obtained by sol gel and spray roasting methods. J Sci Adv Mater Dev. 4, 483-491 (2019). https://doi.org/10.1016/j.jsamd. 2019.07.004

19. Patteck-Janczyck, A., Sepiol, B., Grenier, J.C., Fournes, L.: Double electron exchange in fe1_xo : a mossbauer study. Angewandte Chemie International Edition, 6(11), 951-952. 21, 5-48 (1967)

20. Srinivas, C., Singh, S.B., Tirupanyam, B.V., Meena, S.S., Yusuf, S.M., Prasad, S.A.V., Krishna, K.S.R., Sastry, D.L.: Superparamagnetic behavior of heat treated Mg0.5Zn0.5Fe2O4 ferrite nanoparticles studied by Mössbauer spectroscopy. AIP Conference Proceedings. 1731, 2-5 (2016). https://doi. org/10.1063/1.4947728

21. Vandenberghe, R.E., Barrero, C.A., Da Costa, G.M., Van San, E., De Grave, E.: Mössbauer characterization of iron oxides and (oxy)hydroxides: the present state of the art. Hyperfine Interactions. 126, 247-259 (2000). https://doi.org/10.1023/A:1012603603203

22. Dyar, M.D., Agresti, D.G., Schaefer, M.W., Grant, C.A., Sklute, E.C.: Mössbauer spectroscopy of earth and planetary materials. Annu. Rev. Earth Planet. Sci. 34, 83-125 (2006). https://doi.org/10. 1146/annurev.earth.34.031405.125049

Publisher's note Springer Nature remains neutral with regard to jurisdictional claims in published maps and institutional affiliations. 


\section{Authors and Affiliations}

J. Kargin ${ }^{1} \cdot$ L. De Los Santos Valladares ${ }^{1,2,3,4}$. L. E. Borja-Castro ${ }^{4}$ Jiang Xize ${ }^{3}$.

D. G. Mukhambetov ${ }^{5}$. Y. V. Konyukhov ${ }^{6}$ N. O. Moreno ${ }^{7}$.

A. G. Bustamante Dominguez ${ }^{4}$. C. H.W. Barnes ${ }^{2}$

1 L. N. Gumilyov Eurasian National University, Nur-Sultan, Kazakhstan 010000

2 Cavendish Laboratory, Department of Physics, University of Cambridge, J.J. Thomson Ave, Cambridge CB03 OHE, UK

3 School of materials Sciences and Engineering, Northeastern University, No 11, Lane 3, Wenhua Road, Heping district, Shenyang 110819, People's Republic of China

4 Laboratorio de Cerámicos y Nanomateriales, Facultad de Ciencias Físicas, Universidad Nacional Mayor de San Marcos, Ap. Postal, 14-0146 Lima, Peru

5 Department of Information Systems, Almaty Academy of Economics and Statistics, Almaty, Kazakhstan 050035

6 National University of Sciences and Technology MISIS, Leninsky Ave. 4, 119991 Moscow, Russia

7 Departamento de Física, Universidade Federal de Sergipe, São Cristóvão, SE 49100-000, Brazil 